\title{
Fathers' experiences after having a child: sexuality becomes tailored according to circumstances
}

\author{
Ruth MacAdam, Elisabeth Huuva and Carina Berterö
}

\section{Linköping University Post Print}

N.B.: When citing this work, cite the original article.

Original Publication:

Ruth MacAdam, Elisabeth Huuva and Carina Berterö, Fathers' experiences after having a child: sexuality becomes tailored according to circumstances, 2011, Midwifery, (27), 5, e149e155.

http://dx.doi.org/10.1016/j.midw.2009.12.007

Copyright: Elsevier http://www.elsevier.com/

Postprint available at: Linköping University Electronic Press http://urn.kb.se/resolve?urn=urn:nbn:se:liu:diva-70812 


\section{FATHERS' EXPERIENCES AFTER HAVING A CHILD: SEXUALITY BECOMES TAILORED ACCORDING TO CIRCUMSTANCES}

Ruth MacAdam, RN, CNM, Midwife ${ }^{\mathrm{a}}$

Elisabeth Huuva, RN, CNM, Midwife ${ }^{b}$

Carina Berterö, RNT, BSc, MScN, PhD Professor ${ }^{c}$

a Women's Primary Healthcare Clinic, Örebro, Sweden

b Department of Women's Healthcare Services, Örebro University Hospital, Sweden.

${ }^{c}$ Department of Medical and Health Sciences, Division of Nursing Science, Faculty of Health Sciences, Linköping University, Linköping, Sweden

\section{Corresponding author:}

Carina Berterö, Department of Medical and Health Sciences, Division of Nursing

Science, BSP entrance 62, level 12, Faculty of Health Sciences, Linköpings University, SE-581 85 Linköping, Sweden

Tele: +46 $13227768 \quad$ Fax: +4613123285

E-mail: carina.bertero@liu.se

Word count: 5179 


\section{FATHERS' EXPERIENCES AFTER HAVING A CHILD: SEXUALITY BECOMES TAILORED ACCORDING TO CIRCUMSTANCES}

Abstract

Objective: to identify and describe men's experiences of sexuality after having a child. Design: a qualitative study undertaking an interpretative phenomenological approach for analyzing in-depth interviews.

Participants: purposeful sampling was used. Twelve men were interviewed six to thirteen months after having a child. Informants were men who became fathers for the first time or expanded existing families.

Setting: a mid-sized town located in the mid of Sweden.

Findings: four themes became apparent; a new way of closeness due to non-existing sexuality immediately after birth, the expression of sexuality becomes influenced by the consequences of caring for a child, the expression of love and consideration gives priority over sexual activities and the father's expression of sexuality becomes limited by the lack of reciprocation from the partner.

Key conclusions: after having a child, the expression of sexuality became subjective to the new circumstances created by having a child. Sexuality itself was not experienced any differently, but the expression of sexuality for the fathers became modified depending on how the circumstances presented themselves. Sexuality was extended to different avenues of expression where a sense of belonging evolved and the display of love and affection preceded sexual activities.

Implications for practice: as a health care professional it is important to recall sexuality having various avenues of expression and not only focusing on providing information regarding sexual activities after having a child. Fathers should be invited in the discussion of possible circumstances affecting sexuality to be able to prepare accordingly.

Key Words: Sexuality; Men's experiences; Fatherhood; Interpretive Phenomenology. 


\section{Introduction}

The life event of becoming a father creates permanent changes to a man's existence, leaving an imprint on all aspects of life to come. The phenomena of fatherhood and its impact on life has gained interest within the research community, looking to understand and explain the transition from man to father. St John et al. (2004) describes fatherhood as a time marked by altered family dynamics and social adjustments. Individual challenges of balancing the role of father, provider and partner are influenced and enhanced by social expectations. The renegotiation of roles and the emotions produced by the transition can generate stress and place a strain on the relationship with their partners (St John et al. 2004).

Many studies present findings about men experiencing a deterioration of satisfaction in their relationship after becoming parents (Barclay and Lupton, 1999; Buist et al., 2003; Byrd, 1998; Condon et al., 2004; Dalgas-Pelis, 1993). The stress produced in relation to fatherhood can reduce the relationship satisfaction and generate ongoing problems (Buist et al., 2003) as well as lessen expressed intimacy (Barclay and Lupton, 1999).

Fatherhood and sexuality as also commenced its illumination within current research. In 1999, von Sydow performed a meta-content analysis on the subject of sexuality during pregnancy and after childbirth but found sparse material concerning merely men. Results illustrated men displaying more sexual initiative and interest after pregnancy than the women. Men also associated marital quality with intercourse and tenderness during pregnancy and postpartum. The meta-content analysis stated a need for further studies concerning postpartum sexuality and spurred the upcoming of future research. Current studies are mainly concentrating on sexual functioning (Condon et al., 2004; Gungor et al., 2008; Knauth, 2000; Pastore et al., 2007) or sexual activity and satisfaction (Byrd, 1998; Knauth, 2000; Von Sydow, 2001, 2002; Williamson et al., 2008) and mostly included both partners. The study by Pastore et al. (2007) investigated postpartum sexuality concerns 4-monts and 12 months postpartum among first-time parents. The results confirmed fathers to have multiple areas of concerns relating to sexuality topics extending a year past the birth of the child. These problems were ranging from when to 
resume intercourse to the issue of desire discrepancy between the partners. Twelve months postpartum, the most likely topic left unresolved reflected a mismatched desire, where the sexual needs of the fathers succeeded their partners'. Other studies illustrated dissatisfaction with their sexual relationship (Knauth, 2000) and the men experiencing an overwhelming decline in sexual function that persisted throughout the first year (Condon et al., 2004). How well the relationship and intimacy worked could be linked to the stability and functioning of the relationship prior to having children (Lewis, 1988).

Only one qualitative study concentrating on fatherhood and postpartum sexuality was found in our search. Williamson et al., (2008) conducted a qualitative approach for analyzing random written responses obtained in a questionnaire for first time father on a 6-week postpartum. The majority of responses confirmed a decrease in sexual activity due to lack of time and energy activity, although due the limited responses it is difficult for a deeper insight to be made. Concentrating on the couples' intimate relationship in first-time parents, Ahlborg and Strandmark (2001) conducted a qualitative approach based upon interviews. Results showed the importance of maintaining an open communication as a key aspect for preserving a healthy relationship during the transition into parenthood, regardless of level of intimacy. The absence of being able to express wishes and expectations could leave the man feeling as an outsider with a physical and emotional void.

By concentrating on sexual functioning, activity and satisfaction through qualitative research methods studies concerning men's sexuality postpartum have not viewed sexuality in a holistic approach, where the actual experiences of sexuality can be understood. As described by The Word Health Organization (WHO), 'sexuality goes beyond the acts of erotic activities. It includes all aspects of being and cannot be isolated from other aspects of a person's life, therefore becomes vital for viewing a person as whole. It derives from one's 'sex, gender identities and roles, sexual orientation, eroticism, pleasure, intimacy and reproduction'... and ...'experienced and expressed in thoughts, fantasies, desires, beliefs, attitudes, values, behaviors, practices, roles and relationships' (WHO, 2002). Sheerin and McKenna (2000) analyzed the meaning of sexuality and elicited significant characteristics providing a definition of the expressed 
conditions of sexuality. The foundation of expressing sexuality is manifested by the ability of communicating qualities of one's perceived and accepted sexual identity through mediums such as behaviors, feelings and appearance. The recipient acknowledges, interprets and responds to the communication, which educes a sense of gratification (Sheerin and McKenna, 2000).

According to the research presented above, becoming a father can have great impact on the way sexuality is experienced and expressed. The lack of a holistic approach to the concept of sexuality combined with the few qualitative research designs that have been produced, is leaving men's experiences of sexuality to be a relative unexplored area. To further bring some awareness to this uncharted area of interest, the aim of this study was to identify and describe men's experiences of sexuality, six to thirteen months after having a child.

\section{Method}

This study sought to understand the informants' perspective of lived experience, in a given context, and to elicit meanings from these lived experiences. An interpretive phenomenological approach by Heidegger (Benner, 1994) was compatible with the purpose of the study as it focuses on the participants' world of significant and drawing out meanings from narrative accounts, which are interpreted based upon existing backgrounds. In addition, interpretive phenomenology aims to uncover similarities and distinctions of a phenomenon, which has been expressed by the informants own words, in order to convey awareness (Benner, 1994), reflecting our wish of creating awareness of men's sexuality after having a child. From a hermeneutical/interpretive understanding, the interpretation of meaning is central. Meanings are sought and attention to the questions posed to the text is specified and there is emphasis on the interpreter's foreknowledge of the phenomenon under study (Kvale, 1996).

\section{Sample}

The study was conducted in a midsized town located in the middle of Sweden. Qualified participants were sought out via purposeful sampling. This was mainly achieved by 
individual encounters at appropriate settings, for example organized "father-son" play times gatherings. Informative postings were also placed at various institutions, such as primary health clinics, asking for qualified informants. Appropriate approvals from the head of the departments were obtained prior to visits and distributions of letters. The inclusion criteria were as followed (1) father needed to be >18 years old; (2) had to be in an ongoing relationship with the mother of the baby; (3) be able to communicate fluently in Swedish or English; (4) willing to openly share experiences; (5) the child be between 6-13 months of age and (6) informants should not be known to the interviewers. As to reach an understanding of the phenomena as a whole, the inclusion criteria were not dependent upon the number of children they already fathered. The age of the child was chosen with the intention of the family having time to establish routines and the father provided with sufficient time for being able to reach an understanding of how he experienced sexuality after having a child, as previous research describes the time after delivery as a period of survival and adapting (St John et al., 2005). A total of 13 men were asked to participate, of which 12 were interviewed. The father choosing not to take part in the study did so out of consideration for his partner, who was not comfortable with him sharing intimate information.

Six of the men had children previously and six men were first time fathers. All men were employed, of which 3 were currently on paternity leave with the partner working outside the home. Four of the twelve men were married, the rest co-inhabitant. The median age of the fathers was 33 year of age ranging from 27-45 years. The Study was performed in accordance with the Declaration of Helsinki and Swedish legislation of non-invasive studies (World Medical Association Declaration of Helsinki, 2009; Swedish code of Statutes, 2003). Participants were informed that they could leave the study at any time and the interview material would remain confidential at all times and not to be compared to the experiences of their partners.

\section{Data collection}

Narrative in depth interviewing stimulates spontaneous stories and deemed appropriate for the exploratory research of a person's experiences (Kvale, 2007). The desire was to elicit meanings and commonalities of every day events to develop an understanding that 
can aid people to explore their own view as well as assist the anticipation of future events (Benner, 1994). Each author conducted a pilot interview to enrich skills of interviewing. Twelve men were interviewed during November -08 to April -09 . The informants were allowed to choose the place were the interviews were going to take place as long as privacy could be attained. This was done in order for the participants to feel more relaxed and comfortable in their positions as informants. Interviews were completed at the informant's home or workplace with only the informant and interviewer present. The purpose of the interview was explained upon recruitment and repeated before the start of the interview as to verify their understanding and provide answers to additional questions. An informed consent was obtained at the time of the interview. The informants were interviewed once and interviews were shared equally between authors. In-depth interviews techniques were based on methods described by Kvale (2007). All interviews started with obtaining informants demographics and then followed with an opening query, asking the subjects about their experiences on the subject of sexuality after having a child. The informant was then allowed to freely, without restrictions relate his experiences subjectively. Questions were asked to endorse clarification and/or to further explain areas of interests. This was achieved by repeating significant words in provided answers, using probing questions: please could you tell me more about this, or allowing for periods of silence in the interview (Kvale, 2007). Care was taken not to lead the subject and interfere with minimal interruptions. Notes of behavior, mood, settings and other relevant information were conducted after each interview as an aid for more accurate interpretation in the analysis stage. Interviews ranged between 30 and 50 minutes and were tape-recorded and transcribed ad verbatim. According to Kvale (2007), interview studies generally contain among 15 10 interviews. Based upon the length of the interviews, twelve interviews were deemed appropriate for obtaining adequate material but not too profound for conducting proficient analysis. Names of the informants were substituted to ensure confidentiality.

\section{Data analysis}

The twelve written transcripts were analyzed according to Moustakas (1994) modified method of phenomenology. Prior to analysis both authors clarified their own preconceptions, knowledge and attitudes, which can instigate misinterpretations. As the 
analysis advanced, care was taken to remain true to both method and transcripts, by remaining close to the original text and not constructing meanings out of context (Benner, 1994). As the first step, all transcripts were read multiple times by both authors to achieve a general understanding of the material and reach wholeness. The interviews were then read independently to identify and elicit units, which conveyed meanings of the studied phenomenon. After removing repetitive and overlapping statements, meaning units were clustered into core themes based on subject relevance. Individual textural descriptions were fashioned out of core themes and through imaginative variation and reflection constructed into structural descriptions. By combining all individual texturalstructural descriptions, into a composite emerged the universal description of the essence of the experiences representing the group's experiences as a whole (Moustakas, 1994). Both authors analyzed all interviews, separately and together under the direction of senior author. Findings were read by eight of the informants, who confirmed the authors' findings to be accurately representing the meaning of their lived experiences.

\section{Findings}

The analysis and interpretation from the statements in the transcribed interviews furnished four themes and by interrelation reflected an essence: the expression of sexuality was accepted and modified to the circumstances derived from having a child. The themes producing a foundation for this structure were; A new way of closeness due to non-existing sexuality immediately after birth, the expression of sexuality becomes influenced by the consequences of caring for a child, expression of love and consideration gives priority over sexual activities and the father's expression of sexuality becomes limited by the lack of reciprocation from the partner.

\section{A new way of closeness due to non-existing sexuality immediately after birth}

The initial time after the birth of the child was experienced as a period of survival. All energy and time was directed towards the child, sleep and taking in new impressions. The fathers believed that sexual activities were brought to a natural halt due to the woman's 
physical healing process and felt no distress or frustration over the lack of expressing sexuality.

“...well your sex-life doesn't really bloom after having a child. It creates a situation, you know the woman cannot have sex under a certain time, and maybe I did not feel the need for it either..."

Intimacy and sensuality was for a moment forgotten but channeled by the new situation, a new "two-ness" evolved, which created a new form of closeness. Many of the fathers spoke about the child bringing a new strength and understanding to their relationship.

“...you have a greater understanding for each other why you are tired or sad, and can provide each other with support in different ways, so in that way it has strengthened the relationship. “

Fathers were feeling content with solely expressing a commitment to the family and considered the lack of intimacy and sexual activities to be a natural progression of given circumstances.

\section{The expression of sexuality becomes influenced by the consequences of having a child}

Most fathers experienced a natural return to intimacy and sexual activities.

“...[we] matured at the same time, we felt like, now it's time again.

It was nothing I felt frustrated over, that the sex part did not happen and that she did not feel ready, it took us both the same amount of time..."

Some fathers felt nervous and worried about possibly inflicting pain to their partner due to complications after delivery and therefore waited longer to resume sexual activities. A couple of men mentioned their partner's breasts as "being food stations" rather than 
expressing sexuality. Even though most men noticed their partner's body going through a change, none of them considered it to be affecting their sexuality in a negative way and one father appreciated his partner's new curves. One father expressed feeling less attractive as a man as he was not being able to care for his appearance as much as he used to before having a child.

One man, yet to return to having intercourse ten months after the birth of his son, did express an understanding for his own situation.

“...it was a little boring in the beginning, but after a while it becomes as with anything else you don't miss almost either... but it is really not like I feel, I am so horny, I have to go out and find a replacement, it is not like that."

None of the fathers experienced a change in how they perceived their own sexuality and had "the same feelings and desires" for their partners as they had prior to the birth of the child. But the fathers did noticed a difference in how sexuality was expressed due to new limitations created by adding one more to the family. Sexual acting out became restricted as well as the time for each other, which entailed more planning and "being less spontaneous." All men acknowledged time and energy as key factors for limiting the ability of expressing sexuality.

“...you don't get the time for just being close and sometimes you are tired and don't have the same vigor and sex-drive I can feel"

Other men expressed difficulties in finding privacy in the home. The tension of lacking privacy made sexuality hard to express and created a frustration over constant interruptions.

All fathers except one expressed a decrease in sexual activity, which could vary from almost no difference to noticing a vast change in the frequency of intercourse. The 
display of affection did in most cases remain stable but two men encountered a compensation for the lack of intercourse with " maybe some more kissing and hugging."

The men related their current state of being able to express sexuality acceptable but related it to a limited period that in some cases proved to be the only reason for accepting the current situation.

\footnotetext{
"By the child becoming more predictable we don't need to worry that he is going to wake up at any time and we get more time for each other and can relax more and then the rest comes naturally, affection, love and sexuality"
}

Some men also expressed that it was not possible to achieve the same expression of sexuality they have had prior to having a child but this was also not desired, as having a child was a natural development of their relationship.

\title{
The lack of reciprocation from the partner affected the father's expression of sexuality.
}

\begin{abstract}
All fathers accepted the reduced frequency of sexual activities in respect for their partners' transition into motherhood. However, about half the men experienced difficulties with fulfilling the need for sexual activities after becoming a father and two of the men experiences this as a new situation after having their second child. Their partners did not reciprocate the fathers' needs for sexual activities. The partner "can now be as content with cuddling in bed as I am with having sex." It left the men feeling disappointed and sometimes more eager for confirmation of their sexuality as a man. The fathers also thought there should be more sensuality and intimacy without leading to sexual activities. They understood the situation of not being able to express sexuality the same, but had a hard time accepting the absence of overall sexuality in their partner.
\end{abstract}


“can’t really understand why my partner's desire has to be so much less when mine has not changed"

The men were being active, seeking out opportunities and always initiating the first step; which after a while became a tedious an unrewarding task. They always showed consideration for the partner being tired, and that her sex drive would always precede his own needs. By not acting on the needs for affection and intimacy, fathers were being supportive and considerate to his partners needs.

"Then she falls asleep on the sofa almost every night, it is hard to shake her to life and tell her we are going to have sex"

The fathers could accept having "quick sex" when opportunities emerge, but the partner needed more time to get in the mood and relax.

"...nagging her and asking if we can do it (sex), often I say it jokingly but at same time it lies some truth behind it. Maybe she finds my nagging annoying."

The fathers believed they found more opportunities for sexual activities than their partners' and they realized that intimacy sparked the need for further intimacy.

"The more sex we have, the more we want it."

Fathers sometimes found the experience "dreary, purely frustrating and hard," but deemed it common by receiving confirming information from friends. Being content in the relationship as a whole, prevented the relationship from falling to pieces, but could yield problems in the future if situation became permanent.

In most cases the fathers did not believe the closeness to their partner was influenced by the new addition to the family, although three men noticed a difference in receiving attention and closeness from their partner after having a child. From being the partner's 
first priority and focus of attention, they were now competing for attention, feeling jealous and abandoned..

"I am not usually like this, needing attention in everything I do, but somehow it felt as: look how nice I made it here. So I don't know if it was a counter reaction of feeling left out..."

They believed that caring for the child now satisfied their partner's need for affection and bodily contact. By feeling pushed aside, the experience of feeling close is diminished and therefore harder to achieve intimacy.

\section{Expression of love and consideration gives priority over sexual activities}

Many of the men experienced sexuality as a vital ingredient in their well-being. It made them feel good and provided them with energy, which made it easier to face life's hardships.

“....and partly because I need it for, need it to be happy in my relationship and for me to be happy, for day to day life to work and all that, it means much"

The focus of sexuality now prioritized other areas such as love, sensuality and showing consideration instead of sexual activities.

"You can still show affection and still have a form of sexuality with each other without the intercourse part."

The experience of closeness, just by " lying on the sofa watching a movie and falling asleep holding hands, well just holding each other" or "just hugging" was considered an expression of love and sexuality and could at times be just as important as having intercourse. 
By having less time but more fleeting moments together with their partner, the focus grew to be "the small things" and sexuality became further associated with maintaining a good relationship as a whole. The well-being that was created by sharing responsibilities in the home could not be set apart from a rewarding sexuality. Fulfilling set obligations and helping out with household chores would create a more positive atmosphere for sexual expressions. One father felt as he was walking on eggshells trying to please his partner.

“...thank you for cleaning the kitchen, I don't think that really goes under my definition of sexuality, but it is one part that follows the other."

All fathers stressed the importance of not forgetting to nourish their relationship. This was for some of them gained knowledge from previous experiences in past relationships. The men strived to nurse their relationships by giving daily compliments, showing affection or just being close. Many fathers considered making food and dining together as an especially important way of providing intimacy and maintaining the quality in the relationship.

"We start with good food. We think that is important. Then, we have the time to sit down and talk with each other... see each other..."

A vital part of nursing the relationship was to allow your partner time alone away from home.

"If she has been away for a night and comes home, then she is more in love than ever..."

Fathers also expressed a connection between communication and sexuality and most of them considered communication to lay the foundation for a healthy relationship. 
Communication served as an instrument for sustaining an understanding in the relationship.

"If the communication doesn't work, then the sexuality probably doesn't work and the sex life not especially well either and tenderness and closeness and all that..."

One father stated that the communication that had created intimacy and closeness with his partner was now suffering after having a child, as they now only talked about issues related to keep the family afloat. By not being able to communicate, expressing sexuality became problematic and a feeling of isolation was created "is there something wrong with me."

\section{The Essence; Sexuality becomes tailored according to circumstances}

The structure of the phenomena was experienced as an accepting and limited period in their relationship, where the expression of sexuality became subjective to the new circumstances created by having a child. Sexuality itself was not experienced any differently and the fundamental need for seeking contact and intimacy sustained but the expression of sexuality for the fathers became tailored according to how the situation presented itself. The initial expression of sexuality after birth presented itself with conditions of physical and biological restrictions, which transformed sexuality into a phase relying on the feeling of togetherness. Consumed by caring for the child and making an allowance for their partner's healing process, closeness and affection was conveyed and achieved through a common interest, the child. Later, circumstances became bordered by psychological and emotional conditions and the expression of sexuality progressed into prioritizing love, consideration and showing affection. As the consequences of having a child resulted in tiredness and sexual activities dependent upon the reciprocation of the partner, nurturing the relationship by means of the "small things" became vital for sustaining the need for expressing sexuality. The modifications of expressing sexuality were most commonly viewed as a satisfying experience. 


\section{Discussion}

The goal in the present study was to gain better understanding of how men experienced sexuality after having a child. As the phenomena of sexuality could not be single out from every day life, an interpretative phenomenological approach using in-depth interviews was deemed appropriate to ensure focus on the informant's unique lived experiences (Benner, 1994). As previously mentioned, past research on sexuality and fatherhood demonstrate a limitation in their quantitative nature or basing a qualitative analysis on unexpected written responses in a quantitative questionnaire (Williamson et al., 2006). A quantitative approach will greatly restrict lived experiences to be expressed and understood. The results from present study showed that fathers did not encounter a change in how they experienced sexuality itself, but did acknowledge a difference in the expression of sexuality, according to their individual and unique situations.

Acknowledging time and energy as a cause for changing the expression of sexuality was common for all men and illustrated in earlier studies (Ahlborg and Strandmark, 2001; St John et al., 2004; Williamson et al., 2008). The limited time and often lacking energy created a focus on acknowledging each other through every day life and both previous research and this study confirm a new form of togetherness to evolve between the partners after having a child (Premberg et al. 2008).

Men often expressed the diminished sexual activities as the primary change in displaying sexuality. These findings were supported by similar results of diminished sexual activities after having children (Condon et al., 2004; St John et al., 2004; Von Sydow et al., 1999, 2001; Williamson et al., 2008). The men focused other ways of expressing sexuality and prioritized showing love, affection and consideration. An unanticipated finding was how many fathers emphasized the importance of dining together. This provided them with an opportunity to notice and communicate with each other in their otherwise busy lives as parents. Expressing affection by the "small things" as writing notes and offering compliment became the foundation for sustaining sexuality, thus substituting the lack of sexual activities with affection, consideration and love. Hence, contradictory findings by 
Ahlborg (2004), do not confirm the substitution of sexuality with sensuality, but also do not utilize holistic approach to sexuality by isolating sensuality from sexuality.

Some interviews in this study revealed a mismatched desire when the partners longing for sexual activities diminished after having a child. The development of a desire discrepancy has been established in past research (Pastore et al., 2007; Williamson et al. 2008) where the partner was afraid of displaying affection due to then feeling forced into having intercourse (Ahlborg, 2004). Those findings could explain why the fathers in this research voiced a need for having more intimacy without the requirement for further sexual activities.

Even though the situation at times could create a frustration with the advancement of a desire discrepancy, all men were sympathetic and accepting. None of the fathers exhibited considerable distress or conflict due to the differences in desire for sexual activity and is contradictory to Tomlinson's (2005) results of mismatched desires often creating relationship problems. Further, some second time fathers experienced a desire discrepancy that did not exist with the first child and did not feel more secure about sexual activities postpartum as stated by von Sydow (1999), though could be supported by Wieglos et al. (2007) who illustrated an inverse relationship between the number of children and the quality of sex life: more children means less satisfaction with intimacy. Many of the fathers voiced the importance of upholding communication within the relationship in order to prevent marital problems and linked communication to a gratifying sexuality. Ahlborg (2004) support our results stating how well the intimacy works in a relationship is dependent on the quality of communication. However, particular features of this study exemplify other areas of significance extending beyond the single act of communication. Sexuality becomes marked by various circumstances and how well the expression of sexuality can be tailored accordingly, rather than the communication foretelling the contentment of sexuality.

Further, the importance of integrating fatherhood without giving up one's own person (Premberg et al., 2007), which might explain this study's results of finding time for yourself as well as being together with their partner without children, developed into an essential part for the fathers sexuality and well-being and could re-spark the desire for 
their partners. Sexuality was often expressed as connected with overall well-being and considered to be an essential element in father's lives. Similar findings can be found in other studies (Knauth, 2000; Pastore et al., 2007). Most of the fathers were content with their sexuality after having a child, which were encouraging findings but also a remainder that their happiness was related to judging the situation as a transient phenomenon.

\section{Limitation and strengths}

Twelve fathers who were fairly homogeneous considering age, cultures and socioeconomic standings participated in this research and cannot be generalized to all Swedish men. Though, the researchers believe that adequate richness been given in the description of the phenomena to "enable someone interested in making a transfer to reach a conclusion about whether transfer can be contemplated as a possibility" (Lincoln and Guba, 1985, p 316). A strength in the present study was fashioned by the informants being interviewed alone and knowing that their experiences would not be judged against their partners'. This may possibly aid the stimulation of a more candid and open dialog as sexuality shows to be a complex subject to discuss leaving a person feeling exposed (Tomlinson, 2005). Further, the interviews were conducted by professional female nursemidwifes with many years of combined experience in healthcare related encounters. In the gender aspects of women interviewing men can prove to be beneficial as communication in the male dyad can often be constrained by hierarchical power relationships and protest masculinity (Oliffe and Thorne, 2007), hence there could be some advantages as well regarding men-to-men-talk. To ensure truthful research techniques, each author conducted a test interview to enhance the authors' proficiency in

qualitative interview techniques, and worked in a continued collaboration with an experienced co-author. To aid credibility; eight of the fathers verified that the authors had elicited the true meaning in their lived experiences by taken part of the findings (Guba and Lincoln, 1985). 


\section{Conclusion and recommendation}

As our findings communicate, the expression of sexuality is altered in order to adapt to different circumstances, and sexuality is integrated in every day life and vital to wellbeing. Providing information about sexuality after having a child to both partners as a part of the prenatal care as well as post-natal care seems imperative. Although, the subject of sexuality should be extended to different avenues of expression and placed in relationship to a holistic approach of sexuality and not only include information about sexual activities. It is important that health care professionals focus on explaining the consequences a child can bring to expressing sexuality in a relationship as it could aid the understanding and help the couple to prepare. Additional research should take place to explore the variability that may exist across father of different cultures and backgrounds. 


\section{References}

Ahlborg, T., 2004. Experienced quality of the intimate relationship in first-time parents Qualitative and quantitative studies. Doctoral dissertation. Nordic School of Public Health, Göteborg, Sweden.

Ahlborg T., Strandmark M., 2001.The baby was the focus of attention - first time parents' experiences of their intimate relationship. Scandinavian Journal of Caring Science 15, 318-325.

Barclay L., Lupton D., 1999. The experiences of new fatherhood: a socio-cultural analysis. Journal of Advanced Nursing 29 (4), 1013-1020.

Benner P., 1994. Interpretive Phenomenology: embodiment, Caring, and Ethics in Health an Illness. SAGE Publications Inc., Thousand Oaks, CA.

Buist, A., Morse, C., Durkin S., 2003. Men's Adjustment to Fatherhood: Implications for Obstetric Health Care. Journal of Gynecology and Neonatal Nursing 32, 172-180.

Byrd J., 1998. Sexuality during pregnancy and the year postpartum. Journal of Family Practice 47, 305-308.

Condon, J., Boyce, P., Corkindale C., 2004. The First Time Fathers Study: a prospective study of the mental health and wellbeing of men during the transition to parenthood. Australian and New Zealand Journal of Psychiatry 38, 56-64.

Dalgas-Pelish, P., 1993. The Impact of the first child on marital happiness. Journal of Advanced Nursing 18, 437-441.

Gungor, S., Baser I., Ceyhan, T., Karasahin, E., Kilic S., 2008. Does Mode of Delivery Affect Sexual Functioning of the Man Partner? Journal of Sexual Medicine 5, 155163.

Knauth, D., 2000. Predictors of Parental Sense of Competence For the Couple During the Transition to Parenthood. Research in Nursing \& Health 23, 496-509.

Kvale, S., 2007. Doing Interviews: the Sage Quality Research Kit. The Cromwell Press Ltd., Trowbridge, UK.

Kvale, S., 1996. InterViews. An Introduction to Qualitative Research Interviewing. Sage Publications., London, UK.

Lewis, JM., 1988. The transition to parenthood: I. The rating of prenatal marital competence. Family Process, 27, 149-165.

Lincoln, YS., Guba EG., 1985. Naturalistic inquiry. Sage Publications, Inc., Beverly Hills, CA.

Mc Veigh C., Baafi. A., Williamson M., 2002. Functional Status After Fatherhood: An Australian Study. Journal of Gynecology and Neonatal Nursing 31, 165-171.

Moustakas, C., 1994. Phenomenological Research Methods. SAGE Publications Inc., Thousand Oaks, CA.

Oliffe J., Thorne S., 2007. Communication With Male Physicians

Men, Masculinities, and Prostate Cancer: Australian and Canadian Patient

Perspectives of Communication With Male Physicians. Qualitative Health Research $17,149-161$.

Pastore, L., Owens, A., Raymond, C., 2007. Postpartum Sexuality Concerns Among First-Time Parents from One U.S. Academic Hospital. Journal of Sex Medicine 4, $115-123$.

Premberg, Å., Hellström, A-L., Berg M., 2008. Experiences of the first year as father. Scandinavian Journal of Caring Sciences 22, 56-63. 
Sheerin, F. and Mc Kenna, H., 2000 Defining sexuality for holistic nursing practice: an analysis of the concept. All Ireland Journal of Nursing \& Midwifery 1(3), 94-99.

St. John, W., Cameron, C., Mc Veigh., 2004. Meeting the Challenge of New Fatherhood During the Early Weeks. Journal of Gynecology and Neonatal Nursing 34, 180189.

Swedish code of Statutes, 2003. The act concerning the ethical review of research involving humans. SFS 2003:460. Available at: http://www.epn.se/ start/startpage.aspx. (8 February 2009).

Tomlinson, J., 2005. ABC of Sexual Health, $2^{\text {nd }}$ edition, Blackwell Publishing: Oxford, UK.

von Sydow, K., 1999. Sexuality during pregnancy and after childbirth: a metacontent analysis of 59 studies. Journal of Psychosomatic Research 47, 27-49.

von Sydow, K., 2002. Sexual enjoyment and orgasm postpartum: sex differences and perceptual accuracy concerning partners' sexual experience. Journal of Psychosomatic Obstetric and Gynecology 23, 147-155.

von Sydow, K., Ullmeyer M., Happ N., 2001. Sexual activity during pregnancy and after childbirth: results from the Sexual Preferences Questionnaire. Journal of Psychosomatic Obstetric and Gynecology 22, 29-40.

Wielgos, M,. Jarosz, K., Szymusik, I,. Myszewska, A., Kaminski P., Ziolkowska K., Przybos A., 2007. Family delivery from the standpoint of fathers - Can stereotypes of participant or non-participant father be fully justified? European Journal of Obstetrics \& Gynecology and Reproductive Biology 132, 40-45.

Williamson, M., McVeigh, C., Baafi M., 2008. An Australian perspective of fatherhood and sexuality. Midwifery 24, 99-107.

World Health Organization (WHO), Sexual Health: Working definition; sexuality. Available at: from www.who.int/reproductive-health/gender/sexualhealth.htm\#2. (September 03, 2008 )

World Medical Association Declaration of Helsinki (2009). Available at: http://www.wma.net/e/p olicy/b3.htm. (9 February 2009). 